\title{
Intramolecular Acylal Cyclisation (IAC) as an Efficient Synthetic Strategy Toward the Total Synthesis of Erythrina Alkaloid Derivatives
}

\author{
Alessandra Monaco, ${ }^{[a]}$ Abil E. Aliev ${ }^{[b]}$ and Stephen T. Hilton ${ }^{\star[a]}$
}

\begin{abstract}
Compounds that comprise the Erythrina alkaloid class of Natural products are based on a tetracyclic spironamine framework and exhibit a range of biological activities on the central nervous system. Herein we report a new and efficient total synthesis of this multiple ring system based on an intramolecular acylal cyclisation (IAC) approach. Using this methodology, the tetracyclic core was rapidly assembled over a two step domino process catalysed by a Lewis acid. The effect of heteroatoms, substituents and ring size on the IAC has also been investigated, and the broad application of this procedure is demonstrated by the synthesis of a library of derivatives in good yields with excellent regioselectivity.
\end{abstract}

The Erythrina alkaloid family are a structurally diverse class of biologically active tetracyclic natural products that have been isolated from a number of tropical plant sources (Figure 1). ${ }^{[1]}$ Many members of this calls of compound display a potent effect on the central nervous system (CNS) and as such, have been used in traditional medicine for their anxiolytic, anticonvulsant, sedative, antidepressive and antiepileptic effects. ${ }^{[2]}$ The hydroalcoholic extract of Erythrina mulungu stem bark produces a non-opioid like analgesic effect, ${ }^{[3]}$ whilst neuroethological and neurochemical experiments have demonstrated that extracts of the flowers of $E$. mulungu produce an anxiolytic effect. ${ }^{[4]}$ Several studies have also reported that oral administration of extracts (3, $10,50,100$ and $200 \mathrm{mg} / \mathrm{kg}$ ) produced anxiolytic effects in patients, which was analogous to the effects of diazepam. ${ }^{[5]}$

All members of the Erythrina family possess a distinctive tetracyclic spironamine core and can be classified by variations of the $D$ ring, into three sub-classes with aromatic, heteroaromatic or unsaturated lactone types as shown (Figure 1). ${ }^{[6]}$ As a result of their potent biological activity and challenging structural features, the synthesis of the Erythrina alkaloid core has attracted significant attention over a number of years via a variety of approaches, which have included radical and Pummerer mediated syntheses, intramolecular condensation and Diels-Alder reactions to name but a few. ${ }^{[6,7]}$

Nearly all methods focus on one of two routes to generate the three aliphatic rings, either via a single cyclisation, or via a simultaneous tandem cyclisation approach. ${ }^{[7-8]}$ However, despite

[a] Dr A. Monaco, Dr S.T. Hilton UCL School of Pharmacy University College London

29-39 Brunswick Square, London, WC1N 1AX, United Kingdom E-mail: s.hilton@ucl.ac.uk

[b] Dr A.E. Aliev

Department of Chemistry

University College London

20 Gordon Street, London, WC1H 0AJ, United Kingdom

Supporting information for this article is given via a link at the end of the document. the reported potent biological activities, there has been a surprising lack reports on structural variation of the tetracyclic core. Herein, we not wish to report on our novel approach towards the Erythrina core and related structural derivatives.

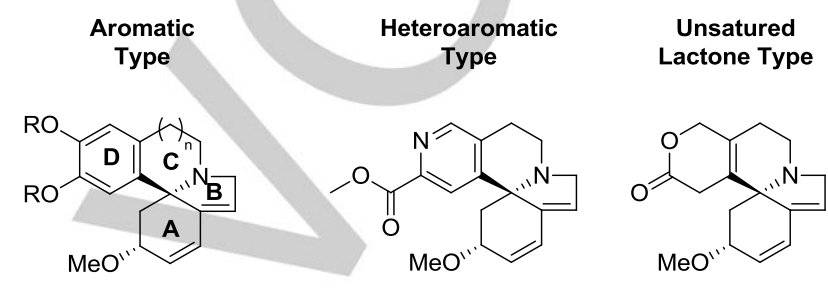

$\mathrm{R}=\mathrm{CH}_{2}: \mathrm{n}=1$; Erythralyne 1

Erymelanthine 4

$\beta$-erythroidine 5

$\mathrm{R}=\mathrm{H}: \quad \mathrm{n}=1$; Erysopine 2

$\mathrm{R}=\mathrm{CH}_{2}: \mathrm{n}=2$; Schelhammeridine 3
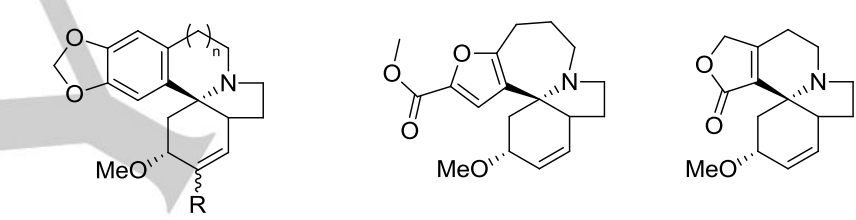

$\mathrm{R}=\mathrm{H}: \mathrm{n}=1$; Erythramine 6

Erymelanthine 8

Cocculolidine 9

Figure 1. Classification of Erythrina alkaloids depending on D ring (aromatic, heteroaromatic and unsaturated lactone types) and on the number of oleofinic bonds (dienoid and alkenoid types).

Following our recent reports on the reactivity and use of acylals, we reasoned that the Erythrina core could be obtained via a Lewis acid mediated intramolecular acylal cyclisation (IAC) to generate rings $B$ and $C$ in a two-step domino process triggered via acylal activation as outlined below (Scheme 1).

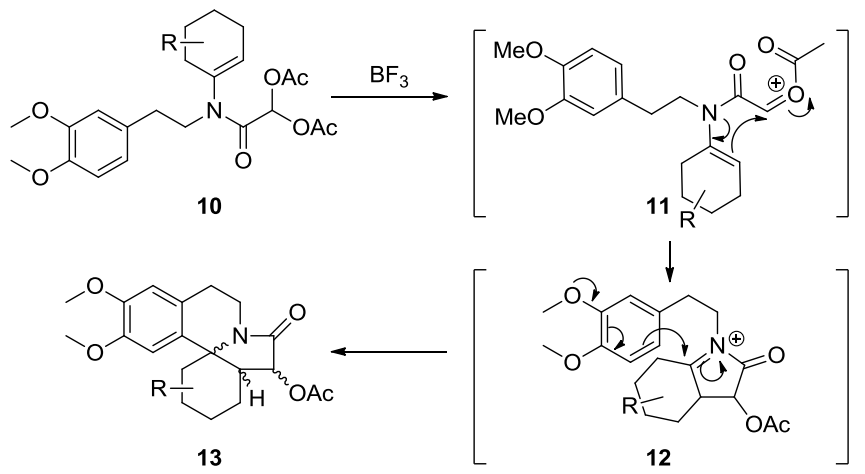

Scheme 1. Cyclisation to generate the tetracyclic core 18.

We envisaged that the cyclisation precursor could be obtained via condensation between a primary amine, cyclohexanone and diacetoxyacetyl chloride (Scheme 1). Under Lewis acid mediated IAC conditions, the enamine would cyclise onto the oxonium species $\mathbf{1 1}$ to generate the intermediate 
imminium ion 12, which would react with the aromatic ring to form the tetracyclic Erythrina core 13. Simple variation of the ketone would therefore provide ready access to a range of analogues in this manner. ${ }^{[9]}$ We decided to use $\mathrm{BF}_{3}$ as the Lewis acid in our cyclisations, due to its mild nature and our previous experience with its reactivity towards diacetoxyamides. ${ }^{[11-14]}$

To investigate our hypothesis, we carried out initia condensation of cyclohexanone and 2-(3,4dimethoxyphenyl)ethanamine $\mathbf{1 4}$ under Dean and Stark water removal conditions. ${ }^{[10]}$ The intermediate imine was reacted immediately with 2-chloro-2-oxoethane-1,1-diyl diacetate ${ }^{[11]} 16$ in the presence of pyridine to afford the key cyclisation precursor $17 \mathrm{a}$ in $63 \%$ yield. Pleasingly, on reaction with $\mathrm{BF}_{3} \mathrm{OEt}_{2}$ (5 equiv.) and microwave heating of the reaction mixture at $65 \stackrel{\circ}{\circ}$ for 15 minutes the tetracyclic core 18a was obtained in good yield $(61 \%)$ and as a single diastereoisomer (Scheme 2).<smiles>COc1ccc(CCN)cc1OC</smiles>

14

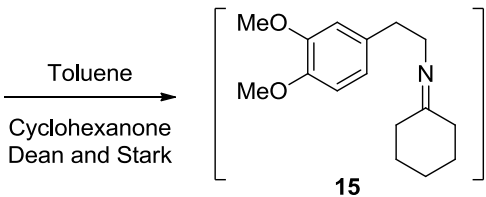

15

$$
\mid \overbrace{16 \text { OAC }}^{\stackrel{O}{H} O A C}
$$

$\checkmark$ Pyridine, DCM

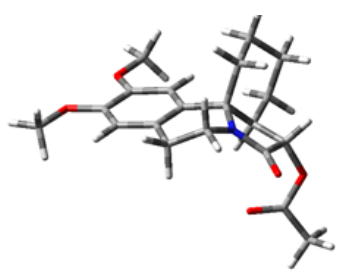

Figure 2. Determination of the relative configuration of the cyclised tetracyclic core structure 18a showing trans configuration around the pyrrolidinone ring.

Following the success in the formation of the Erythrina core, we turned our attention towards formation of a range of closely related analogues via simple variation of the initial ketone component in order to explore the scope of the reaction via variation of ring size and incorporation of heteroatom substituents. The desired cyclisation precursors 17b-17j were prepared in good yields (17-67\%) analogous to the formation of the Erythrina core as shown below (Scheme 3).

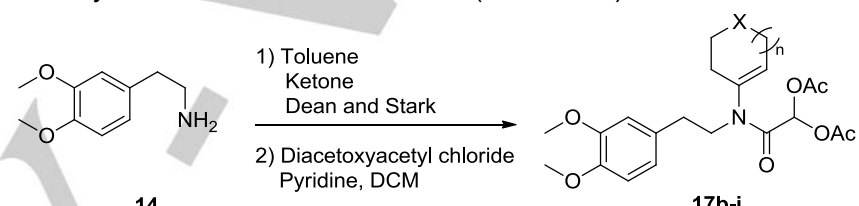
14 $17 b-j$

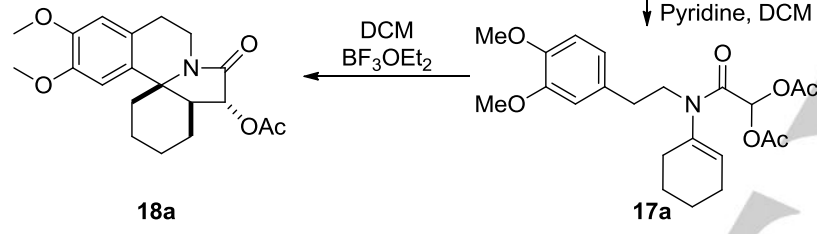

Scheme 2. Mechanism of cyclisation to generate the tetracyclic core 18a.

Whilst it could be anticipated that out of the four potential diastereoisomers, one would be predominant, we were surprised by obtention of a single diastereoisomer in this instance. In order to understand this perhaps surprising selectivity, the relative configuration of the three contiguous chiral centres was determined via NMR $\mathrm{J}$ coupling and NOE measurements of the single diastereoisomer 18a. In combination with computational analysis of the four potential diastereoisomers, ${ }^{[15]}$ the results from energy minimisation calculations and the values from the NMR parameters demonstrated that the hydrogen atoms at C2 and $\mathrm{C} 3$ of the pyrrolidine ring would be configured in a trans relationship as this diastereoisoner is approximately 5.9 $\mathrm{Kcal} / \mathrm{mol}$ more stable than its closest related congener (see Supporting Information for full details of NMR and computational analysis). The results from the NOE studies confirmed these results where the two hydrogen atoms are trans to each other, with a large $\mathrm{J}$ coupling of $10.0 \mathrm{~Hz}$ (Figure 2).

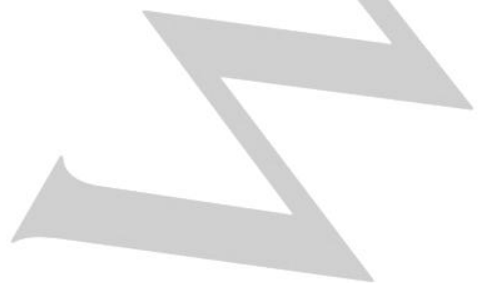

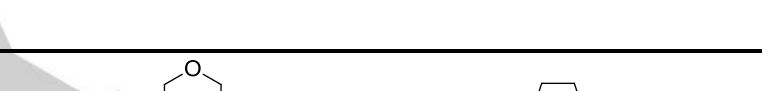

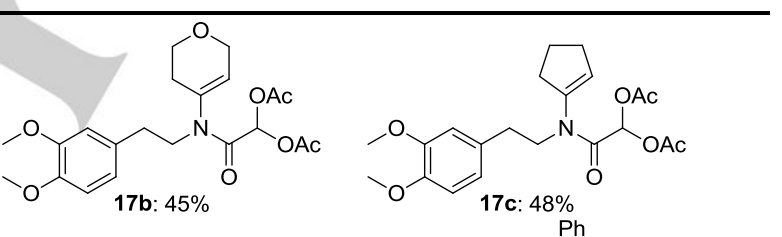<smiles>COc1cc(CCN(C(=O)C(OC(C)=O)OC(C)=O)C2=CCCCC2)cc(OC)c1</smiles><smiles>COc1cc(CCN(C(=O)C(OC(C)=O)C(C)(C)C)C2=Cc3ccccc3CC2)cc(OC)c1OC</smiles><smiles>COc1cc(CCN(C(=O)C(OC(C)=O)C(C)(C)C)C2=CC[C@H](c3ccccc3)CC2)cc(OC)c1</smiles><smiles>COc1cc(CCN(C(=O)C(OC(C)=O)OC(C)=O)C2=CCN(C[PbH3])CC2)cc(OC)c1</smiles><smiles>COc1cc(CCN(C(=O)C(OC(C)=O)OC(C)=O)C2=CCSCC2)cc(OC)c1</smiles><smiles>COc1cc(CCN(C(=O)C(OC(C)=O)OC(C)=O)C2=CCC(C)CC2)cc(OC)c1</smiles><smiles>COc1ccc(CCN(C(=O)C(OC(C)=O)OC(C)=O)C2=CCC(C(F)(F)F)CC2)cc1OC</smiles> 
Compounds $\mathbf{1 7 c}$ and $\mathbf{1 7 d}$ were selected to explore the effect of ring size on diastereoselectivity, whilst the various heteroatom and substituted cyclohexyl rings were chosen to explore the scope of the reaction for the formation of potentially biologically active moieties. All compounds gave good yields of the cyclisation precursors, with the exception of the trifluoromethyl analogue $\mathbf{1 7} \mathbf{j}$, which was a result of the volatility of the starting ketone. Having the cyclisation precursors in hand we focused on their cyclisation to generate Erythrina analogues, the results of which are shown below (Scheme 4).

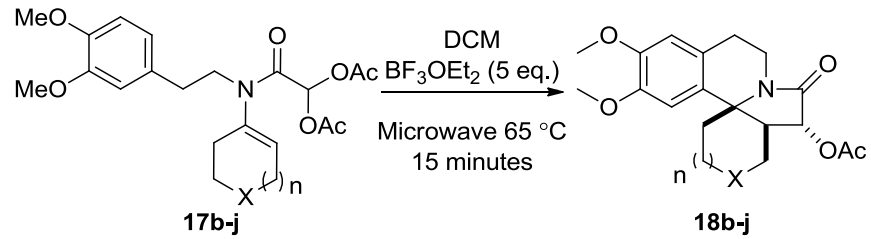

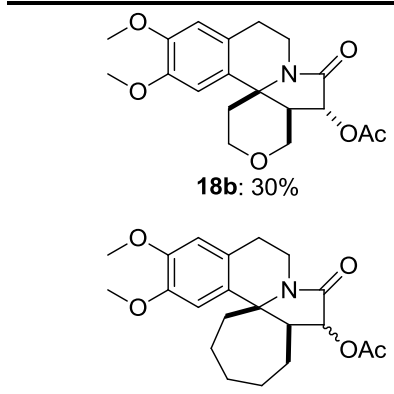

18d: $67 \%$ $60 / 40$ - trans/cis<smiles>COc1cc2c(cc1OC)[C@]1(CCc3ccccc3[C@H]1OC(C)=O)CC2</smiles><smiles>CCN1C(=O)[C@H](OC(C)=O)C2(CCSCC2)c2cc(OC)c(OC)cc21</smiles>

18h: $61 \%$

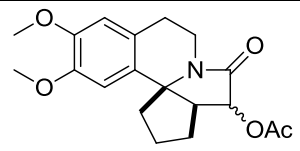

18c: $32 \%$ 85/15 - trans/cis<smiles>COc1cc2c(cc1OC)[C@@]1(CCCC[C@H]1OC(C)=O)[C@H](OC)C2=O</smiles>

Ph

18e: $40 \%$

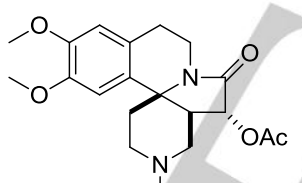

$\mathrm{Ph}$

18g: $59 \%$<smiles>CCN1C(=O)[C@H](OC(C)=O)C2(CCCCC2)c2cc(OC)c(OC)cc21</smiles>

8i: $33 \%$

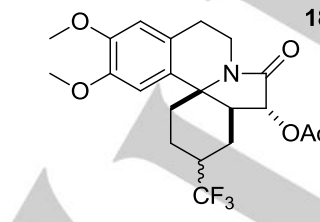

$18 \mathrm{j}: 42 \%$

$0 / 30-$ trans/cis
Scheme 4. Formation of Erythrina tetracyclic analogues.

All reactions were heated in the microwave at $65{ }^{\circ} \mathrm{C}$ for 15 minutes as per the initial reaction with the cyclohexenyl cyclisation precursor $17 \mathrm{a}$. Following purification, it can be readily observed that the cyclised products were obtained in good to excellent yield with good control over diastereoselectivity in most cases. Examination of the results for both the cyclopentyl 18c and cycloheptyl 18d Erythrina analogues demonstrated that the calculations of their respective minimised energies are an effective predictor of the outcome of the diastereoselectivity of cyclisation. In the case of the cyclopentyl analogue $18 \mathrm{c}$, the trans diastereoisomer is $3.9 \mathrm{kcal} / \mathrm{mol}$ more stable than the corresponding cis diastereoisomer and as such, the ratio of trans/cis is $85 / 15$. In the case of the cycloheptyl product $\mathbf{1 8 d}$, the trans diastereoisomer is $0.4 \mathrm{kcal} / \mathrm{mol}$ more stable than the corresponding cis diastereoisomer and as such, the ratio deteriorates to give a trans/cis ratio of $60 / 40$, clearly highlighting that the effect of reducing or increasing ring size leads to a lowering of diastereoselectivity. Incorporation of heteroatom sixmembered analogues of the Erythrina core was well tolerated with compounds $\mathbf{1 8 b}, \mathbf{1 8 g}$ and $18 \mathrm{~h}$ all obtained in good yields (30-61\%) and as single diastereoisomers. Substitution of the cyclohexyl ring in the 4-position was also well tolerated with a phenyl group leading to a single diastereoisomer $18 \mathrm{e}$ in reasonable yield $(40 \%)$, whilst the methyl substituted analogue $18 \mathrm{i}$ and the trifluoromethyl analogue $\mathbf{1 8} \mathbf{j}$ giving reasonable yields of the cyclised products. In the case of $\mathbf{1 8 j}$, the trifluoromethyl group led to a 70/30 mixture of diastereoisomers at the trifluoromethyl position. As per previous six-membered ring containing examples, the diastereoselectivity at the pyrrolodinyl ring was not affected. Pleasingly, we were also able to generate pentacyclic derivatives of the Erythrina core with compound $\mathbf{1 8 f}$ obtained as a single diastereoisomer in $48 \%$ yield and no evidence of any regioisomers.

In summary, we have developed a novel two-step route to the Erythrina core which is based on an intramolecular acylal cyclisation (IAC) approach. In addition, we have shown that by simple variation of the starting ketone, that we can generate a range of substituted analogues with good stereocontrol. Our approach is readily adaptable to incorporation of heteroatom substituents and related pentacyclic derivatives. Further studies on variation of the $D$ ring of the Erythrina core are under way in our laboratories and will be reported in due course.

\section{Acknowledgements}

This work was gratefully supported by an FNS visiting postdoctoral fellowship grant to A.M. [P2GEP2 151840]. We thank the EPSRC UK National Mass Spectrometry Facility at the Swansea University for spectroscopic services.

Keywords: Erythrina - Lewis acid • intramolecular acylal cyclisation $\cdot$ tandem cyclisation $\cdot$ acylal

[1] a) U. P. De Albuquerque, P. M. De Medeiros, A. L. S. De Almeida, J. M. Monteiro, E. M. D. F.L. Neto, J. G. De Melo, J. P. Dos Santos, J. Ethnopharm. 2007, 114, 325-354; b) Y. Tsuda, T. Sano in The Alkaloids, Vol 48 (Ed.: G. A. Cordell), Academic Press, New York, 1996, pp. 249-337

[2] a) A. P. S. Balbani, D. H. S. Silva, J. C. Montovani, Expert Opin. Ther Pat. 2009, 19, 461-473; b) M. E. Garín-Aguilar, J. E. R. Luna, M. SotoHernández, G. V. del Toro, M. M. Vázquez, J. Ethnopharmacol.. 2000 69, 189-196; c) D. S. Rosa, S. A. Faggion, A. S. Gavin, M. A. de Souza 
H. A. Fachim, W. F. dos Santos, A. M. S. Pereira, A. O. S. Cunha, R. O. Beleboni, Epilepsy Behav. 2012, 23, 205-212.

[3] G. M. Onusic, R. L. Nogueira, A. M. S. Pereira, M. B. Viana, Braz. J. Med. Biol. Res. 2002, 35, 473-477.

[4] S. M. M. Vasconcelos, N. M. Lima, G. T. M. Sales, G. M. A. Cunha, L. M. V. Aguiar, E. R. Silveira, A. C. P. Rodrigues, D. S. Macedo, M. M. F. Fonteles, F. C. F. Sousa, G. S. B. Viana, J. Ethnopharmacol. 2007, 110, 271-274

[5] a) J. O. A. Flausino, A. M. Pereira, V. D. S. Bolzani, R. L. Nunes-deSouza, Biol. Pharm. Bull. 2007, 30, 375-378; b) P. Setti-Perdigão, M. A. R. Serrano, O. A. Flausino, V. S. Bolzani, M. Z. P. Guimarães, N. G. Castro, PloS ONE 2013, 8, e82726; c) J. Sarris, E. McIntyre, D. Camfield, CNS Drugs 2013, 27, 207-219.

[6] For recent examples see: a) A. Padwa, H. I. Lee, P. Rashatasakhon, M. Rose, J. Org. Chem. 2004, 69, 8209-8218; b) M. A. Ledreau, D. Desmaele, F. Dumas, J. d'Angelo, J. Org. Chem. 1993, 58, 2933-2935; c) C. L'Homme, M. Ménard, J. Org. Chem. 2014, 79, 8481-8485; d) J. M. Joo, R. A. David, Y. Yuan, C. Lee, Org. Lett. 2010, 12, 5704-5707; d) J. X. Liang, J. B. Chen, J. P. Liu, L. Li, H. B. Zhang, Chem. Commun. 2010, 46, 3666-3668; e) T. Onoda, Y. Takikawa, T. Fujimoto, Y. Yasui, K. Suzuki, T. Matsumoto, Synlett 2009, 1041-1046; f) Y. Yoshida, K. Mohri, K. Isobe, T. Itoh, K. Yamamoto, J. Org. Chem. 2009, 74, 60106015.

[7] For recent examples see: a) B. Juma, M. Adeel, A. Villinger, H. Reinke, A. Spannenberg, C. Fischer, P. Langer, Adv. Synth. Catal. 2009, 351, 1073-1079; b) P. C. Stanislawski, A. C. Willis, M. G. Banwell Org. Lett. 2006, 8, 2143-2146; c) G. Kim, J. H. Kim, K. Y. Lee, J. Org. Chem.
2006, 71, 2185-2187; d) Y. Yasui, K. Suzuki, T. Matsumoto, Synlett 2004, 619-622; d) D. Kalaitzakis, T. Montagnon, E. Antonatou, G. Vassilikogiannakis, Org. Lett. 2013, 15, 3714-3717; e) S. Ogawa, N. lida, E. Tokunaga, M. Shiro, N. Shibata, Chem. Eur. J. 2010, 16, 70907095; f) L. F. Tietze, N. Tolle, D. Kratzert, D. Stalke, Org. Lett. 2009, 11, 5230-5233; g) F. Z. Zhang, N. S. Simpkins, A. J. Blake, Org. Biomol. Chem. 2009, 7, 1963-1979; h) A. Padwa, Q. Wang, J. Org, Chem. 2006, 71, 7391-7402.

[8] Y.-M. Zhao, P. Gu, Y.-Q. Tu, H.-J. Zhang, Q.-W. Zhang, C.-A. Fan, J. Org. Chem. 2010, 75, 5289-5295.

[9] a) C. Bonauer, T. Walenzyk, B. König, Synthesis 2006, 1-20; b) S. P. Lu, A. H. Lewin, Tetrahedron 1998, 54, 15097-15104.

[10] H. I. Lee, M. P. Cassidy, P. Rashatasakhon, A. Padwa, Org. Lett. 2003, 5, 5067-5070.

[11] A. E. Aliev, S. T. Hilton, W. B. Motherwell, D. L. Selwood, Tetrahedron Lett. 2006, 47, 2387-2390.

[12] B. R. Szulc, A. Ruiz, S. T. Hilton, 2014, WO2014181101-A1.

[13] B. C. Sil, S.T. Hilton, Synlett 2013, 2562-2566.

[14] K. M. Cook, S. T. Hilton, J. Mecinovic, W. B. Motherwell, W. D. Figg, C. J. Schofield, J. Biol. Chem. 2009, 284, 26831-26838.

[15] a) A. E. Aliev, Z. A. Mia, H. S. Khaneja, F. D. King, J. Phys. Chem. A 2011, 116, 1093-1109; b) A. E. Aliev, Z. A. Mia, M. J. M. Busson, J. Org. Chem. 2012, 77, 6290-6295. 
Entry for the Table of Contents (Please choose one layout)

Layout 2:

\section{COMMUNICATION}

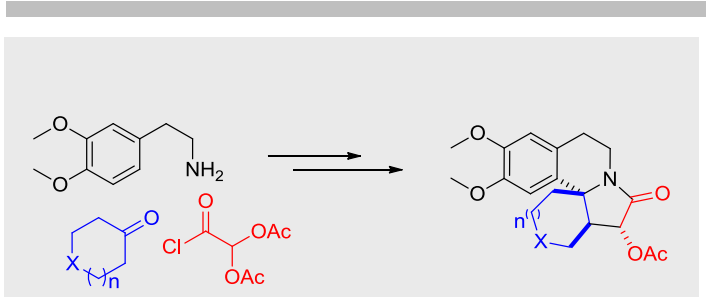

Extending the diversity of the Erythrina core: the tetracyclic core of the Erythrina alkaloid family can be accessed via a Lewis acid mediated intramolecular acylal cyclisation (IAC) approach in two steps. Using this, heteroatoms, and variation of the cyclohexyl ring produced a library of derivatives in good yields and with excellent regioselectivity.
Alessandra Monaco, ${ }^{[a]}$ Abil E. Aliev ${ }^{[b]}$ and Stephen T. Hilton ${ }^{\star[a]}$

Page No. - Page No.

Intramolecular Acylal Cyclisation (IAC) as an Efficient Synthetic Strategy Toward the Total Synthesis of Erythrina Alkaloid Derivatives 